\title{
IRON SHARPENS IRON: A STUDENT'S PERSPECTIVE ON DIVERSITY OUTREACH
}

\author{
THOMAS G. KIMBALL*, RENATA R. HERNANDEZ, MICHAEL S. MINCHER, ANNA L. \\ TREVIÑO
}

\begin{abstract}
*THOMAS.KIMBALL@TTU.EDU; TEXAS TECH UNIVERSITY CENTER FOR COLLEGIATE RECOVERY COMMUNITIES To cite this article: Kimball, T. G., Hernandez, R. R., Mincher, M. S., Trevino, A. L. (2018). Iron Sharpens Iron: A Student's Perspective on Diversity Outreach. Journal of Recovery Science, 1(2), c6. https://doi.org/10.31886/jors.12.2018.20
\end{abstract}

To link to this article: https://doi.org/10.31886/jors.12.2018.20

\begin{abstract}
POWER (Providing the Outside World with Empowerment and Resources), a student organization within the Texas Tech's Collegiate Recovery Program established December 2015, elaborated on their members experience when engaging in the important effort of diversity outreach to persons in recovery from substance and alcohol use disorders and eating disorders. POWER describes their mission statement to provide a foundation and a voice for underrepresented individuals in recovery by delivering positive end results through opportunities for success with a vision to instill hope for a promising future. These members along with the director of the CCRC and another staff member shared what they have found to be most effective and ineffective when presenting to diverse groups in their community. The presenters provided educational and recovery resources used in reaching out but also the varying and tailored approaches and techniques utilized when conducting outreach work to specific marginalized populations. These materials and techniques have been honed through many presentations and experience since 2015. During their presentation, student leaders, and members of POWER, shared their own personal experiences of marginalization as well as their experience as presenters/peer leaders.
\end{abstract}

\section{TREATMENT PROVIDER'S ROLE: PREPARING STUDENTS TO RETURN TO SCHOOL} BOB V. HENNEN*

*BOBH@PAVILLON.ORG; PAVILLON, 241 PAVILLON PLACE MILL SPRING, NC 28756

To cite this article: Hennen, B. V. (2018). Treatment provider's role: Preparing students to return to school. Journal of Recovery Science, 1(2), c6. https://doi.org/10.31886/jors.12.2018.21

To link to this article: https://doi.org/10.31886/jors.12.2018.21

\section{ABSTRACT}

With the continuous growth of the collegiate recovery movement, treatment providers are considering a return to school a viable option for people in early recovery and it is often the goal of the student to return to school as quickly as possible following treatment. The barriers to and skills needed for recovery maintenance and school completion are interconnected and should be addressed simultaneously in treatment with students planning to return to school. This presentation is designed to address the treatment provider's role in preparing a student to return to school by exploring methods to assess for developmental barriers and resources and build skills for both substance use recovery maintenance and the successful navigation of higher education.

All authors approve this manuscript and the original submission. The authors report no conflicts of interest. This work is licensed under the CC-BY license. 